\title{
Editorial
}

\section{Interacción entre espermatozoides humanos y el virus de la inmunodeficiencia humana}

\author{
Walter Cardona Maya*, María Teresa Rugeles**, Ángela P. Cadavid* \\ *Grupo Reproducción. **Grupo de Inmunovirología. Sede de Investigación Universitaria, Universidad de \\ Antioquia, Medellín-Colombia.
}

$\mathrm{L}^{2}$

a infección por el VIH es considerada uno de los principales problemas de salud pública en el mundo. En la actualidad, se calcula que más de 33 millones de personas están infectados con el VIH, lo que indica un incremento de más de 400 veces en el número de infectados que se reportó en $1980^{1}$. En 2007, se presentaron alrededor de 2 millones de muertes relacionadas con el sida, y se reportaron cerca de 2,7 millones de nuevas infecciones ${ }^{1}$. A pesar de que el riesgo de transmisión sexual es tan bajo, más del $80 \%$ de las infecciones con el VIH han sido adquiridas a través de esta vía ${ }^{1}$, sugiriendo un papel importante de los diferentes componentes de las secreciones del tracto genitourinario en esta transmisión. Uno de estos componentes son los espermatozoides, que son las células principales del eyaculado, y cuyo potencial de transmitir el VIH ha sido motivo de debate. La ausencia de expresión de la molécula $\mathrm{CD} 4$, el receptor viral convencional ${ }^{2-4}$, ha sido una de las razones por las cuales se pensó que estas células no tenían esta capacidad; sin embargo, diferentes investigadores han demostrado la presencia de partículas virales en espermatozoides de individuos VIH positivos ${ }^{5-9}$, y la interacción in vitro de espermatozoides humanos con el virus, mediante microscopía electrónica ${ }^{10,11}$.

$\mathrm{El}$ aumento en los casos de infección por el VIH en la población de adultos jóvenes en edad reproductiva, ha incrementado el riesgo no solo de transmisión horizontal, sino también de transmisión vertical de la infección. Diferentes estudios en los cuales se desarrollaron co-cultivo de espermatozoides "infectados" in vitro con mononucleares de sangre periférica $^{11}$ (Cardona-Maya et al., resultados preliminares sin publicar) o con oocitos provenientes de mujeres VIH negativas ${ }^{5}$ demuestran que los espermatozoides tienen la capacidad de transferir el virus a células susceptibles. Sin embargo, a pesar de las diversas evidencias que señalan el potencial de los espermatozoides como una fuente de infección, la interacción directa de estas células con el virus aún no ha sido claramente demostrada. El fin de esta editorial es resaltar el papel de los espermatozoides en la transmisión de la infección del VIH.

Muestras de semen de cuatro individuos VIH negativos $(n=4)$ fueron obtenidas mediante masturbación, posterior a una abstinencia sexual de 3 a 5 días. Después de la licuefacción, 30-60 minutos, cada muestra fue valorada para los parámetros espermáticos siguiendo las recomendaciones establecidas por la OMS. Las diferentes fracciones del eyaculado (plasma seminal, espermatozoides y células no espermáticas como leucocitos) fueron separados por medio de dos gradientes diferenciales (ALLgrad ${ }^{\circledR} 90$ and 45\%, Life Global, Turkey) durante $22 \mathrm{~min} / 560 \mathrm{~g}$ dos veces con el fin de eliminar completamente las células no espermáticas. La fracción recuperada de espermatozoides móviles fue resuspendida en una solución de lavado (ALLgrad Wash ${ }^{\circledR}$, Life Global, Turkey) y centrifugada a $200 \mathrm{~g} / 9 \mathrm{~min}$.

Alrededor de un millón de espermatozoides móviles fueron incubados durante 2 horas a $37^{\circ} \mathrm{C}, 5 \%$ $\mathrm{CO}_{2}$ con $2000 \mathrm{pg} / \mathrm{ml}$ de la proteína p24 del VIH-1, provenientes de las células H9 (H9/HTLV-IIIB NIH 1983); posteriormente, las células espermáticas fueron lavadas 5 veces con HAM-F10 (Sigma Chemical Company, St Louis, MO, USA), para asegurar la eliminación del virus no unido a la membrana celular. Finalmente, los espermatozoides fueron adheridos a portaobjetos, fijados, permeabilizados e incubados con: 1) anti-p24 (KC57-FITC, Coulter) para marcar el virus; 2) phalloidin (C3y) para detectar filamentos de actina y 3) Hoescht para visualizar los núcleos. Las imágenes fueron procesadas usando el programa Pro Plus (MediaCybernetics). 
Para determinar si los espermatozoides interactuaban con la partícula viral se evaluó, por microscopía de fluorescencia, la presencia de la proteína p24 en espermatozoides pre-incubados con el virus. En las Figuras 1 a, b y c se observa un campo en el cual se detecta la presencia del virus, de los filamentos de actina y del núcleo de los espermatozoides, respectivamente. Con el programa Pro Plus (MediaCybernetics), se analizaron las imágenes a través de la reconstrucción en 3D de las imágenes superpuestas (Figs. 1d y 1e), así como la correlación entre las diferentes tinciones (Fig. 1f). El valor de la correlación entre la fluorescencia verde (virus) y la fluorescencia azul (núcleo) en espermatozoides que interactúan con el virus fue de $\mathrm{r}=0,928$ (espermatozoide 1), mientras que en espermatozoides que no presentan interacción con el virus la correlación fue de $r=0,308$ y r=0,109 (espermatozoides 2 y 3, respectivamente). Estos resultados hacen evidente la interacción de los espermatozoides con el VIH-1.

Con base en esta evidencia se puede postular que los espermatozoides humanos tienen la capacidad de interactuar con el VIH in vitro (Fig. 2A), y que esta interacción podría tener un papel importante tanto en la transmisión horizontal como en la transmisión vertical padre a hijo, como fue previamente postulado por nuestro grupo ${ }^{12}$. Sin embargo, a pesar de la evidencia mostrada en estos experimentos, otros ensayos deberán ser realizados con el fin de determinar si el virus tiene la capacidad de entrar al espermatozoide o si el espermatozoide sirve solo como un vehículo para el virus (Fig. 2A). Actualmente, nuestro grupo está trabajando en el diseño de una estrategia metodológica que permita evidenciar la entrada del virus a espermatozoides maduros.

Teniendo en cuenta que los espermatozoides maduros sufren una serie de modificaciones como son: 1) el cambio de histonas por protaminas, el cual se da durante la espermatogénesis, y permite el hiperempaquetamiento del $\mathrm{ADN}$ espermático, 2) la inactividad transcripcional de esta célula debido a la creación del acrosoma, una organela conformada por residuos del aparato de Golgi y retículo endoplasmático, donde se encuentran las enzimas necesarias para atravesar la zona pelúcida ${ }^{13}$, es impor-

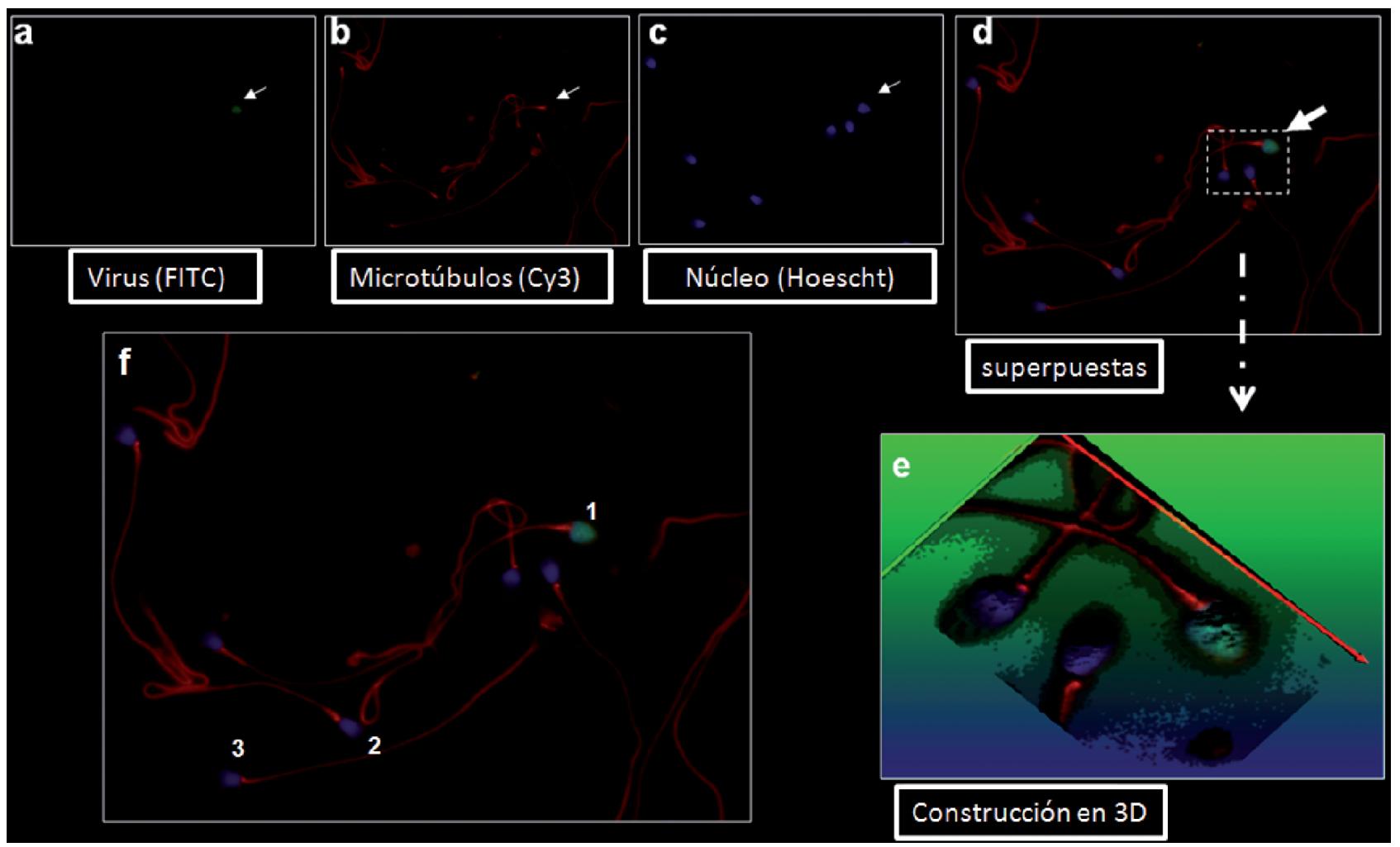

FIGURA 1. Interacción in vitro entre espermatozoides y el virus de la inmunodeficiencia humana. En a, b, $c$ se muestra un campo representativo donde se observa la tinción para el antigeno viral p24, los microtúbulos y el núcleo, respectivamente; $(d, f)$ análisis de las imágenes superpuestas; (e) reconstrucción en $3 D$ procesadas usando el programa Pro Plus (MediaCybernetics), donde se observan particulas virales unidas a un espermatozoide. 


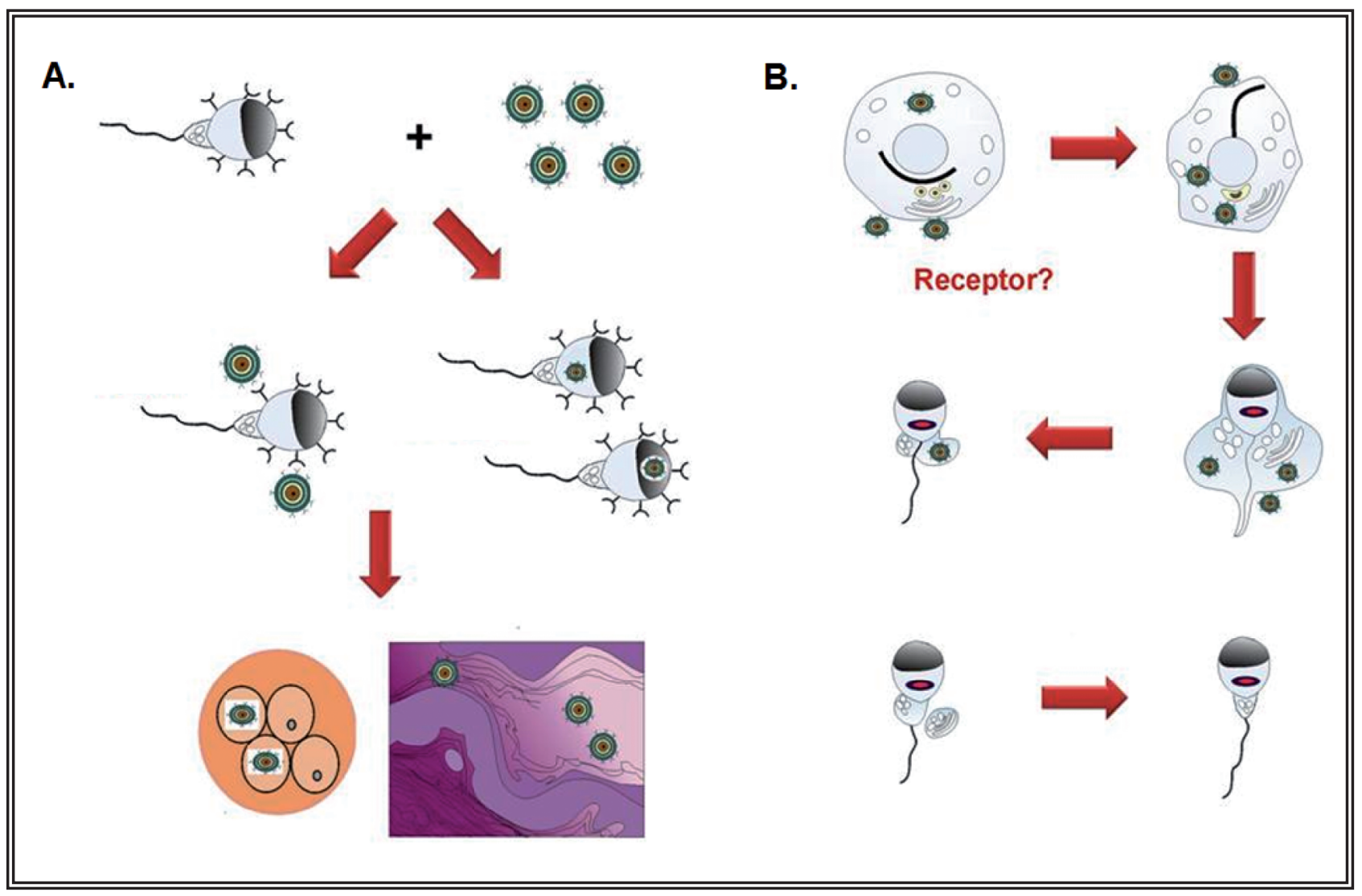

FIGURA 2. Modelos de interacción in vitro (A) $e$ in vivo (B) por el virus de la inmunodeficiencia humana.

tante también evaluar cual sería el resultado de la eventual entrada del virus en el espermatozoide.

Adicionalmente, con base en la evidencia que demuestra la presencia de ADN proviral en espermatozoides maduros ${ }^{5,6,14}$ (datos propios no mostrados) y en células precursoras espermáticas de individuos VIH- 1 positivos ${ }^{6,14}$, se propone un modelo de infección in vivo el cual permite sugerir que la infección de los espermatozoides puede ocurrir durante el proceso de maduración espermática (Fig. 2B). El modo de infección de las espermatogonias es aún incierto; no obstante, algunos autores proponen que estas células inmaduras podrían infectarse a través de la molécula $\mathrm{CD}^{6}{ }^{6}$, receptor que podría estar expresado en las espermatogonias y se perdería durante la espermiogénesis, así como se puede perder el ARN viral durante estos procesos de maduración espermática, permitiendo sólo la permanencia del ADN viral en el espermatozoide.

A pesar de los esfuerzos que diferentes investigadores han realizado para evidenciar el papel del espermatozoide como fuente de transmisión del $\mathrm{VIH}$, estudios adicionales se requieren para poder establecer si las células espermáticas pueden actuar simplemente como un vehículo del virus, o si en ellas se puede dar una infección productiva, abortiva o restrictiva, y si esto va condicionado a su estado de maduración.

\section{Agradecimientos}

Este trabajo fue soportado por el Comité para el Desarrollo de la Investigación (CODI) y por la Facultad de Medicina, Universidad de Antioquía, Medellín, Colombia. Walter Cardona Maya fue soportado por una beca de Colciencias, Colombia.

\section{REFERENCIAS}

1. UNAIDS. UNAIDS 2008 Report on the global AIDS epidemic 2008.

2. Ashida ER, Scofield VL. Lymphocyte major histocompatibility complex-encoded class II structures may act as sperm receptors. Proc Natl Acad Sci U S A1987 May;84(10):3395-3399.

3. Kim LU, Johnson MR, Barton S, Nelson MR, Sontag G, Smith JR, et al. Evaluation of sperm washing as a potential method of reducing HIV transmission in HIV-discordant couples wishing to have children. Aids. 1999;13(6):645-651.

4. Wolff H, Schill WB. Determination of sperm antibodies in human genital secretions by an ELISA technique. Hum Reprod. 1988;3 (2):223-225. 
5. Baccetti B, Benedetto A, Burrini AG, Collodel G, Ceccarini EC, Crisa N, et al. HIV-particles in spermatozoa of patients with AIDS and their transfer into the oocyte. J Cell Biol. 1994;127(4):903-914.

6. Bagasra O, Farzadegan H, Seshamma T, Oakes JW, Saah A, Pomerantz RJ. Detection of HIV-1 proviral DNA in sperm from HIV-1-infected men. Aids. 1994;8(12):1669-1674.

7. Barboza JM, Medina H, Doria M, Rivero L, Hernandez L, Joshi NV. Use of atomic force microscopy to reveal sperm ultrastructure in HIV-patients on highly active antiretroviral therapy. Arch Androl. 2004;50(2):121-129.

8. Muciaccia B, Corallini S, Vicini E, Padula F, Gandini L, Liuzzi $\mathrm{G}$, et al. HIV-1 viral DNA is present in ejaculated abnormal spermatozoa of seropositive subjects. Hum Reprod. 2007;22 (11):2868-2878.

9. Muciaccia B, Filippini A, Ziparo E, Colelli F, Baroni CD, Stefanini M. Testicular germ cells of HIV-seropositive asymptomatic men are infected by the virus. J Reprod Immunol. 1998; 41(1-2):81-93.

10. Baccetti B, Benedetto A, Collodel G, di Caro A, Garbuglia AR, Piomboni P. The debate on the presence of HIV-1 in human gametes. J Reprod Immunol. 1998;41(1-2):41-67.
11. Dussaix E, Guetard D, Dauguet C, D'Almeida M, Auer J, Ellrodt A, et al. Spermatozoa as potential carriers of HIV. Res Virol. 1993;144(6):487-495.

12. Cardona-Maya W, Lopez-Herrera A, Velilla-Hernandez P, Rugeles MT, Cadavid AP. The role of mannose receptor on HIV1 entry into human spermatozoa. Am J Reprod Immunol. 2006;55(4):241-245.

13. Yanagimachi R. Fertilization in Mammalian. In: Knobil E NJ, editor. The Physiology of Reproduction. New York: Raven Press Ltd.; 1994;89-318.

14. Nuovo GJ, Becker J, Simsir A, Margiotta M, Khalife G, Shevchuk M. HIV-1 nucleic acids localize to the spermatogonia and their progeny. A study by polymerase chain reaction in situ hybridization. Am J Pathol. 1994;144(6):1142-1148.

Correspondencia autor: Dr. Walter Cardona Maya Grupo Reproducción. Sede de Investigación Universitaria Universidad de Antioquia, Medellín-Colombia Tel.: 57 (4) 2196685

E-mail autor: wdcmaya@medicina.udea.edu.co. Información artículo: Editorial

Trabajo recibido: enero 2009 